\title{
Cost analysis of the very elderly admitted to intensive care units
}

\author{
Nicolas Chin-Yee ${ }^{1 *}$, Gianni D'Egidio ${ }^{1}$, Kednapa Thavorn² ${ }^{2}$ Daren Heyland ${ }^{3}$ and Kwadwo Kyeremanteng ${ }^{1}$
}

\begin{abstract}
Background: Very elderly patients are often admitted to intensive care units (ICUs) despite poor outcomes and frequent preference to avoid unnecessary prolongation of life. We sought to determine the cost of ICU admission for the very elderly and the factors influencing this cost.

Methods: This prospective, observational cohort study included patients $\geq 80$ years old admitted to 22 Canadian ICUs from 2009 to 2013. A subset of consenting individuals comprised a longitudinal cohort followed over 12 months. Costs were calculated from ICU length of stay and unit costs for ICU admission from a Canadian academic hospital. A generalized linear model was employed to identify cost-predictive variables.

Results: In total, 1671 patients were included; 610 were enrolled in the longitudinal cohort. The average age was 85 years; median ICU length of stay was 4 days. Mortality was 35\% (585/1671) in hospital and 41\% (253/610) at 12 months. The average cost of ICU admission per patient was $\$ 31,679 \pm 65,867$. Estimated ICU costs were $\$ 48,744$ per survivor to discharge and $\$ 61,783$ per survivor at 1 year. For both decedents and survivors, preference for comfort measures over life support was an independent predictor for lower cost $(P<0.01)$.

Conclusions: Considering the poor clinical outcomes, and that many ICU admissions may be undesired by very elderly patients, ICU costs in this population are substantial. Our finding that a preference for comfort care predicted a lower cost independent of mortality reinforces the importance of early goals of care discussions to avoid both undesired and potentially non-beneficial interventions, consequently reducing costs.
\end{abstract}

Trial registration: ClinicalTrials.gov, NCT01293708. Registered on 10 February 2011.

Keywords: Critical illness, Cost of care, Octogenarian, End-of-life care, Outcome assessment

\section{Background}

Very elderly (aged 80 or older) patients are being admitted to intensive care units (ICUs) in increasing numbers [1-3]. More concerning is that these admissions may occur despite the preference of many elderly patients to avoid unnecessary prolongation of life by life-sustaining therapy [4-6]. In spite of this, more than $70 \%$ of seriously ill hospitalized elderly patients do not discuss these preferences with their healthcare providers [6], which may result in provision of life-sustaining therapy even when patients prefer care focused on improved comfort and quality of life [7-10].

\footnotetext{
* Correspondence: nchinyee@toh.ca

'Department of Medicine, University of Ottawa/The Ottawa Hospital, 501

Smyth Rd., Ottawa, Ontario K1H 8L6, Canada

Full list of author information is available at the end of the article
}

In our prospective, observational cohort of very elderly patients admitted to ICUs in Canada, not only was hospital and 12-month mortality high [11], but surviving individuals had a low probability of returning to baseline physical function [12]. Other studies have corroborated the findings of poor short- and long-term outcomes in this patient population [13-16]. These observations raised important questions about the appropriateness of both admission to and long-term treatment in the ICU for this population.

There is presently unprecedented strain on the healthcare system in the face of the baby boomer effect and increases in life expectancy [17], and critical care remains amongst the most expensive of healthcare interventions, consuming approximately $1 \%$ of the GDP $[18,19]$. These costs continue to rise, and are expected to increase further as the incidence of critical illness requiring ICU 
admission is projected to increase by $80 \%$ by $2026[19$, 20]. There are significant economic implications surrounding admission of very elderly patients to the ICU, as the costs of providing prolonged and potentially nonbeneficial care in this population are likely considerable. While ICU costs in elderly patients have been reported in smaller retrospective and prospective cohorts, estimates have ranged widely depending on the type of cost presented and the method of cost estimation [21-25].

The primary objective of this study was to determine contemporary costs of care for very elderly patients admitted to ICUs using our large prospective Canadian cohort. In addition, we sought to determine potentially predictive patient and family factors influencing cost of care.

\section{Methods}

\section{Study design and population}

As described in previous reports [11, 12], the data source for this study was a prospective cohort of patients 80 years of age or older admitted to 22 Canadian ICUs between September 2009 and January 2013. Briefly, all eligible patients whose hospital records were abstracted, based on research coordinator availability, were included in an unselected "hospital cohort", which captured patient demographics and clinical outcomes for the index hospital admission. A subset of the hospital cohort from whom written informed consent was obtained (from patients and/or their primary caregivers) comprised a "longitudinal cohort" followed over 12 months, which described 12-month mortality and additional patient features, including family preferences for life-sustaining therapy. For this cohort, we excluded patients who remained in the ICU for less than $24 \mathrm{~h}$, as well as nonresidents of Canada and patients who did not have available family members or whose family members spoke neither English nor French. All those in the hospital cohort not fulfilling these exclusion criteria were approached for consent for the longitudinal study. Written informed consent was obtained from patients and/or their legal representatives before enrolment, and subsequently from competent, surviving patients for the follow-up assessment. Eligible family members (which included partners, significant others, and close friends) provided the most unpaid care to the patient, visited the patient at least once during ICU admission, and were at least 18 years of age. Local Research Ethics Board approval was obtained from all participating institutions.

\section{Outcome measures and explanatory variables}

The primary outcome measure of this study was the ICU cost, which was calculated by multiplying total ICU length of stay for each patient by an average daily ICU cost per patient in 2012/13, derived using the case- costing system within the Ottawa Hospital Data Warehouse. This case-costing system estimates total daily direct and indirect costs by taking the sum of costs of each functional centre, such as medications and laboratory tests, incurred by each patient for each ICU day. The system is based on a standardized costing methodology developed by the Ontario Case Costing Initiative according to the Canadian Institute for Health Information Management Information Systems guidelines [26]. The average daily ICU cost per patient was obtained by dividing total ICU costs incurred between April 2012 and March 2013 by the total number of ICU patient days during the same period.

To estimate adjusted hospital costs, we included the following variables in our regression analyses: age, sex, primary ICU admitting diagnosis, admission type (medical, surgical elective, surgical emergency), Charlson comorbidity index [27], Acute Physiology and Chronic Health Evaluation (APACHE) II score [28], and Sequential Organ Failure Assessment (SOFA) score at admission [29]. Additional variables studied for the longitudinal cohort included patient frailty (as per the Rockwood Clinical Frailty Score [30], where a score of $>4 / 7$ was considered frail), residence in a nursing home, family preference for lifesustaining therapy, and presence of an advance directive. As explained in greater detail in the initial report [11], for family preference for life-sustaining therapy, patients' family members were asked to choose between life support, comfort measures without life support, and "I am unsure". Only the presence of an advance directive was recorded; contents of these directives were not captured.

\section{Statistical analyses}

Cost of ICU was expressed as the mean ( \pm standard deviation) of ICU admission per patient in Canadian Dollars. We estimated ICU cost per survivor to discharge and per survivor at 1 year from total ICU costs and mortality in the hospital and longitudinal cohorts, respectively. A generalized multivariable linear regression model using a log link function and gamma distribution was employed to predict ICU costs while controlling for other factors. This regression was performed separately for survivors and hospital decedents. Results were expressed as standardized (beta) coefficients with 95\% confidence intervals (CIs). $P$ values less than 0.05 were considered statistically significant. All analyses were performed using SAS (Version 9.3, Cary, NC, USA).

\section{Results}

Patient characteristics and clinical outcomes

Of 3064 patients aged 80 years or older admitted to ICUs who were screened for eligibility, 1671 had hospital records abstracted and were included in the hospital cohort; 610 of these consented to be enrolled in the 
longitudinal cohort. Table 1 summarizes the baseline characteristics and clinical outcomes of patients aged 80 years or older admitted to ICUs for both the hospital and longitudinal cohorts, as described in previous reports $[11,12]$. In the hospital cohort, median ICU length of stay was 4 days and 585 patients (35\%) died in hospital. In the longitudinal cohort, median ICU length of stay was 6 days, 158 patients (26\%) died in hospital, and 253 (41\%) were deceased within 12 months. With respect to family preferences for life-sustaining treatment, 310 (51\%) preferred life support, 129 (21\%) desired comfort care without life support, and 171 (28\%) were

Table 1 Baseline characteristics and clinical outcomes of study patients

\begin{tabular}{|c|c|c|}
\hline Characteristic/outcome & $\begin{array}{l}\text { Hospital cohort } \\
(n=1671)\end{array}$ & $\begin{array}{l}\text { Longitudinal cohort } \\
(n=610)\end{array}$ \\
\hline Age (years) & $85 \pm 3$ & $84 \pm 3$ \\
\hline Sex (male) & $915(55 \%)$ & $338(55 \%)$ \\
\hline Admission APACHE II score & $22 \pm 8$ & $22 \pm 7$ \\
\hline Baseline SOFA score & $5 \pm 3$ & $5 \pm 3$ \\
\hline Charlson comorbidity index & $2 \pm 2$ & $2 \pm 2$ \\
\hline \multicolumn{3}{|l|}{ Admission type } \\
\hline Medical & $1,033(62 \%)$ & $377(62 \%)$ \\
\hline Surgical elective & $220(13 \%)$ & $83(14 \%)$ \\
\hline Surgical emergency & $418(25 \%)$ & $150(25 \%)$ \\
\hline \multicolumn{3}{|l|}{ Primary ICU admitting diagnosis } \\
\hline Cardiovascular & $408(24 \%)$ & $143(23 \%)$ \\
\hline Respiratory & $389(23 \%)$ & $157(26 \%)$ \\
\hline Gastrointestinal & $298(18 \%)$ & $110(18 \%)$ \\
\hline Sepsis & $178(11 \%)$ & $72(12 \%)$ \\
\hline Other & $398(24 \%)$ & $128(21 \%)$ \\
\hline Frailty index $>4 / 7$ & N/A & $193(32 \%)$ \\
\hline Residence in a nursing home & N/A & $24(4 \%)$ \\
\hline \multicolumn{3}{|c|}{ Family preference for life-sustaining treatment } \\
\hline Life support & N/A & $310(51 \%)$ \\
\hline $\begin{array}{l}\text { Comfort care without life } \\
\text { support }\end{array}$ & N/A & $129(21 \%)$ \\
\hline Unsure/unclear/missing & N/A & $171(28 \%)$ \\
\hline Presence of advance directive & N/A & $300(49 \%)$ \\
\hline Median ICU length of stay & $4(2-8)$ & $6(3-10)$ \\
\hline Median hospital length of stay & $17(8-33)$ & $21(12-40)$ \\
\hline Mean ICU length of stay & $9 \pm 19$ & $8 \pm 9$ \\
\hline Mean hospital length of stay & $9 \pm 21$ & $11 \pm 14$ \\
\hline Hospital mortality & $585(35 \%)$ & $158(26 \%)$ \\
\hline 12-month mortality & N/A & $253(41 \%)$ \\
\hline
\end{tabular}

Values are shown as mean \pm standard deviation, median (interquartile range), or count (\%). APACHE Acute Physiology and Chronic Health Evaluation, ICU intensive care unit, N/A not applicable, SOFA Sequential Organ Failure Assessment score unsure or had not specified their preference. Threehundred (49\%) patients had an advance directive.

\section{Cost of ICU admission}

Table 2 illustrates separately the cost of ICU admission for survivors and decedents in both cohorts. The average costs of ICU admission per patient were $\$ 31,679 \pm 65,867$ and $\$ 36,158 \pm 34,222$ for the hospital and longitudinal cohorts, respectively. For the hospital cohort, the cost of ICU in survivors was $\$ 27,833 \pm$ 46,359 while the cost in non-survivors was $\$ 38,820 \pm$ 91,294 .

With respect to outcomes, the estimated total ICU cost was $\$ 48,744$ per survivor to discharge (hospital cohort) and $\$ 61,783$ per survivor at 1 year (longitudinal cohort) (Fig. 1). This estimation does not include costs of hospitalization following ICU discharge.

\section{Predictive variables}

Table 3 demonstrates the multivariate linear regression results for predictive variables for cost of ICU admission performed separately for survivors to discharge and decedents in hospital. For survivors and decedents, respectively, older age was associated with lower cost (coefficient $=-0.139,95 \% \mathrm{CI}-0.021$ to $-0.007, P=0.039$; coefficient $=-0.029,95 \% \mathrm{CI}-0.051$ to $-0.007, P=0.008$ ) and respiratory primary ICU diagnosis was associated with a greater cost (compared with cardiovascular diagnosis; coefficient $=0.461,95 \%$ CI 0.294 to $0.627, P=$ 0.000 ; coefficient $=0.690,95 \%$ CI 0.270 to $1.111, P=$ 0.001). Amongst patients who died in hospital, a greater baseline SOFA score, but not greater comorbidity index or APACHE II score, was associated with lower cost (coefficient $=-0.084,95 \%$ CI -0.114 to $-0.053, P=0.000$ ). For survivors, increased comorbidity index was a

Table 2 Cost of ICU admission for very elderly patients

\begin{tabular}{llll}
\hline Group & $n$ & \multicolumn{2}{l}{ Cost of ICU admission per patient } \\
\cline { 3 - 4 } & & Mean & Standard deviation \\
\hline Hospital cohort & & & \\
All patients & 1,671 & 31,679 & 65,867 \\
All patients, per day & 1,671 & 3520 & 7749 \\
Survivors to discharge & 1,086 & 27,833 & 46,359 \\
Decedents in hospital & 585 & 38,820 & 91,294 \\
Longitudinal cohort & & & \\
All patients & 610 & 36,158 & 34,222 \\
All patients, per day & 610 & 4520 & 3845 \\
Survivors to discharge & 452 & 31,323 & 31,228 \\
Decedents in hospital & 158 & 49,989 & 38,491
\end{tabular}

Costs are presented in Canadian Dollars. Costs of ICU admission were calculated by ICU length of stay and both indirect and variable direct costs for ICU admission at The Ottawa Hospital in 2012-2013. ICU intensive care unit, SD standard deviation 


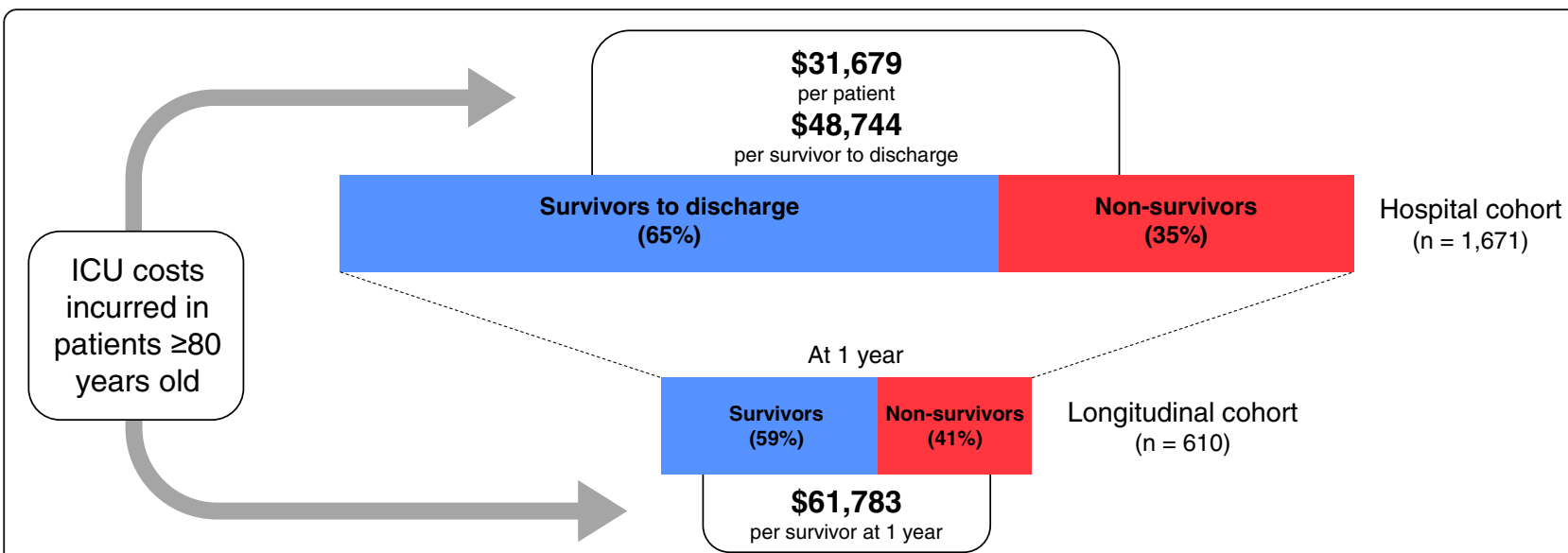

Fig. 1 Intensive care unit (ICU) costs in very elderly patients with respect to mortality. Average cost of ICU admission per patient (hospital cohort) and calculated total ICU cost per survivor to discharge and at 1 year. The longitudinal cohort was a selected cohort of individuals from the hospital cohort followed over a 1-year period. Costs are presented in Canadian Dollars

predictor for lower cost (coefficient $=-0.035,95 \% \mathrm{CI}$ -0.069 to $-0.000, P=0.048)$, and higher APACHE II score was a predictor for greater cost (coefficient $=$ $0.031,95 \%$ CI 0.023 to $0.039, P=0.000$ ); SOFA score was not significantly associated with the cost of ICU care in this group.
Compared with patients whose families preferred life support, those with a family member specifying a preference for comfort care without life support had a significantly lower ICU cost in both survivors and decedents (coefficient $=-0.253,95 \% \mathrm{CI}-0.433$ to $-0.073, P=0.006$; coefficient $=-0.402,95 \% \mathrm{CI}-0.650$ to $-0.155, P=0.001$,

Table 3 Multivariate model for predictors of ICU cost in very elderly patients

\begin{tabular}{|c|c|c|c|c|}
\hline Variable & Coefficient $(95 \% \mathrm{Cl})$ & $P$ value & Coefficient $(95 \% \mathrm{Cl})$ & $P$ value \\
\hline Hospital cohort $(n=1671)$ & \multicolumn{2}{|c|}{ Survivors to discharge $(n=1,086)$} & \multicolumn{2}{|c|}{ Decedents in hospital $(n=585)$} \\
\hline Age (older) & $-0.139(-0.021,-0.007)$ & 0.039 & $-0.029(-0.051,-0.007)$ & 0.008 \\
\hline Sex (female) & $-0.092(-0.207,0.022)$ & 0.113 & $-0.034(-0.289,0.221)$ & 0.796 \\
\hline Admission APACHE II score (greater) & $0.031(0.023,0.039)$ & 0.000 & $0.001(-0.012,0.014)$ & 0.926 \\
\hline Baseline SOFA score (greater) & $-0.005(-0.028,0.018)$ & 0.661 & $-0.084(-0.114,-0.053)$ & 0.000 \\
\hline Charlson comorbidity index (greater) & $-0.035(-0.069,-0.000)$ & 0.048 & $0.024(-0.019,0.067)$ & 0.281 \\
\hline \multicolumn{5}{|l|}{ Admission type } \\
\hline Surgical elective vs. medical & $-0.133(-0.287,0.021)$ & 0.091 & $0.193(-0.191,0.577)$ & 0.324 \\
\hline Surgical emergency vs. medical & $0.076(-0.065,0.218)$ & 0.290 & $0.091(-0.169,0.351)$ & 0.494 \\
\hline \multicolumn{5}{|l|}{ Primary ICU diagnosis } \\
\hline Respiratory vs. cardiovascular & $0.461(0.294,0.627)$ & 0.000 & $0.690(0.270,1.111)$ & 0.001 \\
\hline Gastrointestinal vs. cardiovascular & $0.150(0.004,0.295)$ & 0.043 & $0.277(-0.088,0.642)$ & 0.137 \\
\hline Sepsis vs. cardiovascular & $0.177(-0.029,0.382)$ & 0.092 & $0.538(0.238,0.839)$ & 0.000 \\
\hline Other vs. cardiovascular & $0.174(0.020,0.328)$ & 0.027 & $-0.210(-0.463,0.042)$ & 0.103 \\
\hline Longitudinal cohort $(n=610)$ & \multicolumn{2}{|c|}{ Survivors to discharge $(n=452)$} & \multicolumn{2}{|c|}{ Decedents in hospital $(n=158)$} \\
\hline Frailty index $>4 / 7$ & $-0.001(-0.071,0.069)$ & 0.977 & $0.044(-0.044,0.132)$ & 0.325 \\
\hline Residence in a nursing home & $-0.321(-0.633,-0.010)$ & 0.043 & $0.046(-0.485,0.577)$ & 0.864 \\
\hline \multicolumn{5}{|l|}{ Family preference for life-sustaining treatment } \\
\hline Comfort care vs. life support & $-0.253(-0.433,-0.073)$ & 0.006 & $-0.402(-0.650,-0.155)$ & 0.001 \\
\hline Unsure/unclear/missing vs. life support & $-0.429(-0.635,-0.223)$ & 0.000 & $-0.393(-0.814,0.028)$ & 0.067 \\
\hline Presence of advance directive & $0.122(-0.050,0.294)$ & 0.165 & $0.214(-0.010,0.438)$ & 0.061 \\
\hline
\end{tabular}

Generalized linear model using a log function. Cost distribution closely matched gamma distribution (incorporated into model). Regression was performed separately for each cohort, and for both survivors and decedents. See Additional file 2 (Table S1) for the complete regression results for the longitudinal cohort. APACHE II Acute Physiology and Chronic Health Evaluation score, CI confidence interval, ICU intensive care unit, SOFA Sequential Organ Failure Assessment score 
respectively). Neither clinical frailty nor the presence of an advance directive were significantly associated with the cost of ICU care. Although residence in a nursing home was associated with a lower cost of care amongst survivors (coefficient $=-0.321,95 \%$ CI -0.633 to -0.010 , $P=0.043$ ), it was not a significant cost predictor in those who died in hospital.

\section{Discussion}

In this multicentre cohort study, we demonstrated the significant cost of ICU admission in very elderly patients-approximately $\$ 32,000$ per patient. Despite this cost, clinical outcomes were poor: $35 \%$ of patients died in hospital and $41 \%$ of those followed longitudinally were deceased at 1 year. This amounts to an ICU cost alone of nearly $\$ 49,000$ per survivor to discharge for the unselected cohort, and $\$ 62,000$ per survivor at 1 year amongst those in the longitudinal study. In addition, we demonstrated important patient and family factors that influence the cost of care; specifically, a preference for comfort measures over life support was an independent predictor for lower cost of care, and remained a predictor for both survivors and decedents.

Our reported cost of ICU admission in very elderly Canadians of $\$ 31,679$ per patient is considerably higher than most studies reporting the cost of ICU care in similar populations [21-25]. Interpretation of cost differences between studies, however, remains inaccurate and may be misleading given the various types of costs reported and differences in methods of cost calculation. As a result, previous studies that calculated the cost of ICU admission in elderly and very elderly patients report a wide range of costs, from approximately $\$ 3300$ to $\$ 28,100$ USD per patient [21-25]. The daily ICU cost per patient in the present study, however, was similar compared with reported figures from cohorts that also included non-elderly adult patients [18, 25, 31]. For Canadian adults, a recent report estimated an average daily ICU cost of $\$ 3592$ with an average length of stay in the ICU of 3 days [32]. Altogether, the similar daily cost but longer total length of stay in the ICU for the very elderly patients in our cohort compared to the general adult ICU population likely accounts for the notably higher overall cost of ICU admission [31, 32]. Although some studies suggest that very elderly patients admitted to ICU may incur fewer costs compared to their younger counterparts as a result of less aggressive care, our study did not directly compare costs to younger patient cohorts or study the costs associated with specific interventions [21, 22]. This trend towards fewer invasive interventions in very elderly patients, however, was not observed in our cohort, $85 \%$ of whom received at least one form of life-sustaining therapy and $72 \%$ of whom were mechanically ventilated [11], contrasting with the estimated rate of mechanical ventilation in the general adult ICU population in Canada of 33\% [32]. This might, in fact, suggest that average daily ICU costs may underestimate costs for elderly patients and overestimate costs for younger adults.

The cost of ICU stay for the very elderly becomes more striking when contemplated in light of clinical outcomes observed in this population. Without even considering the costs of non-ICU hospitalization or readmission, long-term care, and outpatient care, the cost of ICU alone in our study was over $\$ 60,000$ per survivor at 1 year. Though 1 -year mortality was greater than $40 \%$ in our study, other investigators have reported that long-term mortality may be even higher in this group (55-90\% at 3 years) $[15,16,33]$. Furthermore, we recently showed, in the same cohort as the present study, that at 1 year only $26 \%$ of patients had survived and recovered back to, or near, their baseline level of functioning [12]. As such, the ICU and non-ICU costs per functional survivor are likely substantially higher than the exclusive ICU costs we present. Potential explanations for the differences in mortality and length of stay between the hospital and longitudinal cohorts are discussed in greater detail in earlier reports [11, 12].

Even more important than the clinical outcomes were the apparent incongruences between patient/family wishes and the provision of life-sustaining treatment received, which many elderly patients would have preferred to avoid [4-6]. Nearly one quarter of patients or their caregivers in the present study had an expressed preference for comfort measures over life support, yet were admitted to ICU and received life-sustaining therapy. These observations should prompt healthcare providers to re-evaluate the benefit of ICU care for the very elderly, and suggest that patients' preferences and goals of care are not addressed early enough to prevent unwanted healthcare interventions or ICU admissions.

Mechanical ventilation has been shown to increase ICU costs [31]. This may partially explain why respiratory diagnoses in our cohort were associated with the highest costs in our study. The observation that cardiovascular diagnoses were the least costly probably reflects the inclusion of post-operative cardiac and vascular surgery patients in this group-patients who may have more predictable ICU courses, preselected based on fitness for surgery. Perhaps not surprisingly, older age and greater SOFA scores in non-survivors were associated with a lower cost, likely because they were predictors of earlier mortality. In survivors to discharge, why older age was a predictor of lower cost and why we observed conflicting results with respect to comorbidity index and illness severity scores as costpredictive factors remains unclear.

Interestingly, we found that patients whose family members had specified a preference for comfort care 
over life support had a significantly lower cost of ICU care, not only for those who died in hospital, but also for survivors to discharge. This finding suggests that, without adversely affecting clinical outcomes, an approach that focuses early on comfort measures instead of life support led to a reduction in cost. This is corroborated by our recent work which demonstrated that palliative care consultation reduced ICU length of stay [34].

The main limitations to our study surrounded the calculation of ICU cost. Our cost estimates were based on figures from a single academic institution, and therefore do not account for variability in costs between institutions and the known lower costs in the community ICU setting [32]. Additionally, costs were estimated by ICU dates of admission (length of stay), and therefore specific costs of care for each patient were not captured. These are known limitations to this validated method of cost calculation [35]. Finally, inpatient and outpatient costs of care following ICU discharge were not ascertained, and would be an important consideration as many of these patients have extended hospitalizations and a prolonged recovery period.

\section{Conclusions}

Our large multicentre cohort provides a unique and representative population to define the cost of critical care for the very elderly, which is higher than in the general adult ICU population despite more than double the ICU mortality rate [32]. Considering that very elderly patients frequently express a desire for a good quality of life over lifesustaining therapy, our finding that a family preference for comfort care was a predictor for lower ICU cost provides further impetus for early goals of care discussion and the development of tools for recognition of patients with probable poor outcomes [36]. Our reported cost figures will be important to inform future clinical, policymaking, and funding decisions aiming to reduce financial strain on our medical system and ensure appropriate allocation of healthcare resources. Ultimately, this will require systemic changes in end-of-life care, specifically surrounding the decisions to continue life-sustaining therapy for an elderly patient with multiple comorbidities in the ICU.

\section{Additional files}

Additional file 1: List of participating centres. (DOCX $37 \mathrm{~kb}$ )

Additional file 2: Table S1. Multivariate model of ICU cost in very elderly patients: longitudinal cohort $(n=610)$. (DOCX $13 \mathrm{~kb})$

\section{Abbreviations}

APACHE II: Acute Physiology and Chronic Health Evaluation II; Cl: Confidence interval; ICU: Intensive care unit; SOFA: Sequential Organ Failure Assessment

\section{Acknowledgements}

The authors would like to thank Sasha van Katwyk for his assistance with statistical analysis.

\section{Funding}

This study was funded by the Canadian Institutes of Health Research.

Availability of data and materials

Not applicable.

\section{Authors' contributions}

NCY contributed to study design, analysis and interpretation of data, and drafting of the manuscript. GD participated in study design and revised the manuscript. KT supervised the data analysis and revised the manuscript. DH participated in study design, interpretation of data, and revision of the manuscript. KK contributed to study design, analysis and interpretation of data, and revision of the manuscript. All authors read and approved the final manuscript.

\section{Competing interests}

The authors declare that they have no competing interests.

\section{Consent for publication}

Not applicable.

\section{Ethics approval and consent to participate}

Local Research Ethics Board approval was obtained from all participating institutions (see Additional file 1). Written informed consent was obtained from patients and/or their legal representatives before enrolment.

\section{Publisher's Note}

Springer Nature remains neutral with regard to jurisdictional claims in published maps and institutional affiliations.

\section{Author details}

${ }^{1}$ Department of Medicine, University of Ottawa/The Ottawa Hospital, 501 Smyth Rd., Ottawa, Ontario K1H 8L6, Canada. ${ }^{2}$ Ottawa Hospital Research Institute, The Ottawa Hospital, Ottawa, Ontario, Canada. ${ }^{3} \mathrm{Clinical}$ Evaluation Research Unit, Kingston General Hospital, Kingston, Ontario, Canada.

Received: 26 November 2016 Accepted: 2 May 2017

Published online: 16 May 2017

\section{References}

1. Wunsch H, Linde-Zwirble WT, Harrison DA, Barnato AE, Rowan KM, Angus DC. Use of intensive care services during terminal hospitalizations in England and the United States. Am J Respir Crit Care Med. 2009;180(9): 875-80.

2. Bagshaw SM, Webb SA, Delaney A, George C, Pilcher D, Hart GK, et al. Very old patients admitted to intensive care in Australia and New Zealand: a multi-centre cohort analysis. Crit Care. 2009:13(2):R45.

3. Ball IM, Bagshaw SM, Burns KE, Cook DJ, Day AG, Dodek PM, et al. Outcomes of elderly critically ill medical and surgical patients: a multicentre cohort study. Can J Anaesth. 2017:64(3):260-69.

4. Heyland DK, Dodek P, Rocker G, Groll D, Gafni A, Pichora D, et al. What matters most in end-of-life care: perceptions of seriously ill patients and their family members. CMAJ. 2006;174(5):627-33.

5. Philippart F, Vesin A, Bruel C, Kpodji A, Durand-Gasselin B, Garcon P, et al. The ETHICA study (part I): elderly's thoughts about intensive care unit admission for life-sustaining treatments. Intensive Care Med. 2013;39(9): 1565-73.

6. Heyland DK, Barwich D, Pichora D, Dodek P, Lamontagne F, You J, et al. Failure to engage hospitalized elderly patients and their families in advance care planning. JAMA Intern Med. 2013;173(9):778-87.

7. Hofmann JC, Wenger NS, Davis RB, Teno J, Connors Jr AF, Desbiens N, et al. Patient preferences for communication with physicians about end-of-life decisions. SUPPORT Investigators. Study to Understand Prognoses and Preference for Outcomes and Risks of Treatment. Ann Intern Med. 1997; 127(1):1-12

8. Giannini A, Pessina A, Tacchi EM. End-of-life decisions in intensive care units: attitudes of physicians in an Italian urban setting. Intensive Care Med. 2003; 29(11):1902-10.

9. The SUPPORT Principal Investigators. A controlled trial to improve care for seriously ill hospitalized patients. The study to understand prognoses and 
preferences for outcomes and risks of treatments (SUPPORT). JAMA. 1995; 274(20):1591-8.

10. Covinsky KE, Fuller JD, Yaffe K, Johnston CB, Hamel MB, Lynn J, et al. Communication and decision-making in seriously ill patients: findings of the SUPPORT project. The Study to Understand Prognoses and Preferences for Outcomes and Risks of Treatments. J Am Geriatr Soc. 2000;48(5 Suppl): S187-93.

11. Heyland D, Cook D, Bagshaw SM, Garland A, Stelfox HT, Mehta S, et al. The very elderly admitted to ICU: a quality finish? Crit Care Med. 2015;43(7): 1352-60.

12. Heyland DK, Garland A, Bagshaw SM, Cook D, Rockwood K, Stelfox HT, et al. Recovery after critical illness in patients aged 80 years or older: a multicenter prospective observational cohort study. Intensive Care Med. 2015; 41(11):1911-20.

13. Garrouste-Orgeas M, Timsit JF, Montuclard L, Colvez A, Gattolliat O, Philippart F, et al. Decision-making process, outcome, and 1-year quality of life of octogenarians referred for intensive care unit admission. Intensive Care Med. 2006;32(7):1045-51.

14. Boumendil A, Latouche A, Guidet B, Group I-CS. On the benefit of intensive care for very old patients. Arch Intern Med. 2011;171(12):1116-7.

15. Boumendil A, Maury E, Reinhard I, Luquel L, Offenstadt G, Guidet B. Prognosis of patients aged 80 years and over admitted in medical intensive care unit. Intensive Care Med. 2004;30(4):647-54.

16. Kaarlola A, Tallgren M, Pettila V. Long-term survival, quality of life, and quality-adjusted life-years among critically ill elderly patients. Crit Care Med. 2006;34(8):2120-6.

17. Oeppen J, Vaupel JW. Demography. Broken limits to life expectancy. Science. 2002;296(5570):1029-31.

18. Halpern NA, Pastores SM. Critical care medicine in the United States 20002005: an analysis of bed numbers, occupancy rates, payer mix, and costs. Crit Care Med. 2010;38(1):65-71.

19. Halpern NA, Goldman DA, Tan KS, Pastores SM. Trends in critical care beds and use among population groups and medicare and medicaid beneficiaries in the United States: 2000-2010. Crit Care Med. 2016;44(8): 1490-9.

20. Needham DM, Bronskill SE, Calinawan JR, Sibbald WJ, Pronovost PJ, Laupacis A. Projected incidence of mechanical ventilation in Ontario to 2026: preparing for the aging baby boomers. Crit Care Med. 2005;33(3):574-9.

21. Boumendil A, Aegerter P, Guidet B, Network CU-R. Treatment intensity and outcome of patients aged 80 and older in intensive care units: a multicenter matched-cohort study. J Am Geriatr Soc. 2005;53(1):88-93.

22. Chelluri L, Mendelsohn AB, Belle SH, Rotondi AJ, Angus DC, Donahoe MP, et al. Hospital costs in patients receiving prolonged mechanical ventilation: does age have an impact? Crit Care Med. 2003;31(6):1746-51.

23. Chelluri L, Pinsky MR, Donahoe MP, Grenvik A. Long-term outcome of critically ill elderly patients requiring intensive care. JAMA. 1993;269(24): 3119-23.

24. Chelluri L, Pinsky MR, Grenvik AN. Outcome of intensive care of the "oldestold" critically ill patients. Crit Care Med. 1992;20(6):757-61.

25. Montuclard L, Garrouste-Orgeas M, Timsit JF, Misset B, De Jonghe B, Carlet J. Outcome, functional autonomy, and quality of life of elderly patients with a long-term intensive care unit stay. Crit Care Med. 2000;28(10):3389-95.

26. Wodchis WP, Bushmeneva K, Nikitovic M, McKillop I. Guidelines on personlevel costing using administrative databases in Ontario. Toronto: Health System Performance Research Network; 2012

27. Charlson ME, Pompei P, Ales KL, Mackenzie CR. A new method of classifying prognostic comorbidity in longitudinal studies: development and validation. J Chronic Dis. 1987;40(5):373-83.

28. Knaus WA, Draper EA, Wagner DP, Zimmerman JE. APACHE II: a severity of disease classification system. Crit Care Med. 1985;13(10):818-29.

29. Moreno R, Vincent JL, Matos R, Mendonca A, Cantraine F, Thijs L, et al. The use of maximum SOFA score to quantify organ dysfunction/failure in intensive care. Results of a prospective, multicentre study. Working Group on Sepsis related Problems of the ESICM. Intensive Care Med. 1999;25(7): 686-96

30. Rockwood K, Song X, MacKnight C, Bergman H, Hogan DB, McDowell I, et al. A global clinical measure of fitness and frailty in elderly people. CMAJ. 2005;173(5):489-95.

31. Dasta JF, McLaughlin TP, Mody SH, Piech CT. Daily cost of an intensive care unit day: the contribution of mechanical ventilation. Crit Care Med. 2005; 33(6):1266-71
32. Canadian Institute for Health Information. Care in Canadian ICUs. Ottawa: $\mathrm{ClHI} ; 2016$.

33. Broslawski GE, Elkins M, Algus M. Functional abilities of elderly survivors of intensive care. J Am Osteopath Assoc. 1995;95(12):712-7.

34. Kyeremanteng K, Gagnon LP, Thavorn K, Heyland D, D'Egidio G. The impact of palliative care consultation in the ICU on length of stay: a systematic review and cost evaluation. J Intensive Care Med. 2016. PMID 27582396.

35. Kahn JM, Rubenfeld GD, Rohrbach J, Fuchs BD. Cost savings attributable to reductions in intensive care unit length of stay for mechanically ventilated patients. Med Care. 2008;46(12):1226-33.

36. Heyland DK, Stelfox HT, Garland A, Cook D, Dodek P, Kutsogiannis J, et al. Predicting performance status 1 year after critical illness in patients 80 years or older: development of a multivariable clinical prediction model. Crit Care Med. 2016;44(9):1718-26.

\section{Submit your next manuscript to BioMed Central and we will help you at every step:}

- We accept pre-submission inquiries

- Our selector tool helps you to find the most relevant journal

- We provide round the clock customer support

- Convenient online submission

- Thorough peer review

- Inclusion in PubMed and all major indexing services

- Maximum visibility for your research

Submit your manuscript at www.biomedcentral.com/submit
Biomed Central 